\title{
Executive processes in Asperger syndrome: Patterns of performance in a multiple case series
}

\author{
Elisabeth L. Hill ${ }^{\mathrm{rb}}$, Chris M. Bird ${ }^{\mathrm{b}}$ \\ a Department of Psychology, Goldsmiths College, University of London, New Cross, London SE14 6NW, \\ United Kingdom $\mathrm{b}$ Institute of Cognitive Neuroscience, University College, London, United Kingdom
}

\begin{abstract}
Mixed evidence exists for executive dysfunction in autism spectrum disorders (ASD). This may be because of the nature of the tasks used, the heterogeneity of participants, and difficulties with recruiting appropriate control groups. A comprehensive battery of 'executive' tests was administered to 22 individuals with Asperger syndrome and 22 well-matched controls. Performance was analysed both between groups and on an individual basis to identify outliers in both the ASD and control groups. There were no differences between the groups on all 'classical' tests of executive function. However, differences were found on newer tests of executive function. Specifically, deficits in planning, abstract problem solving and especially multitasking. On the tests that discriminated the groups, all of the ASD individuals except one were identified as significantly impaired (i.e. below the $5^{\text {th }}$ percentile of the control mean) on at least one executive measure. This study provides evidence for significant executive dysfunction in Asperger syndrome. Greatest dysfunction appeared in response initiation and intentionality at the highest level-the ability to engage and disengage actions in the service of overarching goals. These deficits are best observed through using more recent, ecologically valid tests of executive dysfunction. Moreover, performance on these measures correlated with autistic symptomatology.
\end{abstract}

Keywords: Executive functions; Autism spectrum disorder; Problem solving; Multitasking; Prefrontal cortex 
'Executive function' is traditionally used as an umbrella term for abilities such as planning,working memory, impulse control, inhibition and shifting set, as well as the initiation and monitoring of action (Roberts, Robbins, \& Weiskrantz, 1998; Stuss \& Knight, 2002). Animal, behavioural and neuropsychological studies have linked these functions to frontal structures of the brain, and to prefrontal cortex in particular. Additionally, a number of neurodevelopmental disorders have been linked to executive dysfunction, including autism spectrum disorder (ASD; see Russell, 1997). The core features of autism are abnormalities of social interaction, impairments in verbal and non-verbal communication and a restricted repertoire of interests and activities, all present from early childhood (American Psychiatric Association, 1994). If executive dysfunction is a central component of ASD then this would have important implications for diagnosis, intervention and our theoretical understanding of the syndrome. However, the presence, or causal nature of executive dysfunction to autism is much debated.

Systematic reviews of the literature reveal mixed evidence for executive dysfunction in ASD, although difficulties in planning, mental flexibility and generativity have been documented (see Pennington, \& Ozonoff, 1996, for review). Mixed findings may arise from a number of issues, including the nature of the tasks administered as well as the nature of the autism and/or control samples used. In its strongest form, seeing executive dysfunction as a core and causal deficit in ASD would imply that it should be found in all ASD populations, irrespective of age and/or general ability. Thus for example, if a child had a planning deficit, you would expect that child to continue to show a planning deficit in some form as an adult. Moreover, if specific executive functions play a causal role in ASD, these would be expected to correlate with severity of autistic symptomatology.

Given the, at times, equivocal results of past studies, it is necessary to conduct a study that addresses possible causes of contradictory findings. In the current study, we have attempted to do this on three counts. First, Asperger syndrome might be considered to be the purest form of autism in the sense that it is unimpeded by the effects of learning difficulty common to other parts of the autism spectrum (Frith, 2004). Individuals with Asperger syndrome have IQs well within the normal range, they tend to have been educated in mainstream schools and may even be diagnosed only in adulthood. Yet they experience striking difficulties in the core areas of autistic dysfunction. Therefore, any deficits that are related causally to autistic symptomatology should be found in their most pure forms in high-functioning individuals with ASD, i.e. those with Asperger syndrome. Second, we report data from a group of adults, rather than children, for which only a handful of previous studies have been published (see Table 1). By focusing on this group, we can avoid issues concerning the late maturation of the frontal lobes (Mesulam, 2002) that may cloud the picture in studies of children and adolescents as we are tapping into an apparently mature executive system. Furthermore, others have argued recently for the need to focus on the study of executive functions in adults with ASD in order to understand the possible causal role of executive function and dysfunction within the autistic spectrum (Lopez, Lincoln, Ozonoff, \& Lai, 2005). Third, by carefully selecting an IQmatched control group we move away from complications in interpreting results in the light of ability level, since the interpretation of performance of a clinical group can be influenced strongly by selection of controls.

As an umbrella term, 'executive functions' is rather vague. A range of functions are included, and the term is often confused at different levels of explanation; namely, constructs, operations and functions (see Burgess et al., 2006, for elaboration). Briefly, in their example, Burgess et al. argued that the function working memory is a construct. An operation refers to each individual component of that construct that is not directly observable, but inferred (the mental manipulation of representations, for example), and a function is the output of a series of operations that is, itself, observable. A whole range of tests purport to measure some aspects of executive function. These tests include those well-known, 'classic' tests of executive function such as the tower tasks (e.g. Tower of Hanoi), Wisconsin Card Sort Task (WCST), the Stroop test and tests of verbal fluency. Studies with children with ASD have shown plenty of dissociations between performance on these tests (see Hill, 2004a). However, it is unclear what the pattern of 
performance of adults with AS is across various executive processes, or even whether there is consistency in performance on two measures believed to assess the same component of executive function.

Another difficulty is the choice of tasks that can be used to assess executive functioning reliably. Standard tests of executive function tend to be complex tasks, where the outcome is the sum of performance of a number of executive processes. For example, Tower tasks are often taken as a measure of planning. However, these involve a number of processes over and above planning per se (e.g. working memory, inhibition of prepotent but inefficient sub-goal moves). Furthermore, traditional tests of executive function may be insensitive in those with a putative developmental executive dysfunction, in a way that they are not in those with acquired executive dysfunction.

A further factor that needs to be investigated to clarify the nature of any executive dysfunction in ASD is the method of analysis. Studies have focused on group comparisons, concluding that executive dysfunction exists in ASD when a significant group difference is found between the performance of the ASD group in comparison to a control group. However, this approach alone is problematic since individual differences tend to be large. In fact, it has been argued that aggregating data across a group of individuals requires that all individuals are homogenous with respect to their cognitive profiles, and this cannot be assumed a priori (McCloskey, 2001). Consequently non-significant group differences are not indicative of fully intact performance in all participants. Conversely, in studies with large numbers of individuals, 'significant' differences in performance at the group level may be largely meaningless in terms of the degree of executive dysfunction exhibited by the individuals within the group if there is a large degree of overlap between the groups. By careful, detailed analyses of individual cases, rich information can be obtained concerning the range of performance, and the potential of difficulties in a subgroup of individuals (Caramazza \&McCloskey, 1988; Marshall\&Newcombe, 1984; McCloskey, 2001). In the current study we conducted both a group analysis of performance on our test battery and also a detailed analysis of the 22 individual cases.

Anecdotal accounts of the everyday difficulties of adults with high-functioning forms of ASD are suggestive of difficulties in executive functioning. Indeed, Channon, Charman, Heap, Crawford, and Rios (2001) reported that according to parents, a group of individuals aged 10-19 years with Asperger syndrome showed significantly more behaviours associated with dysexecutive syndrome than did a typically developing group. This was assessed using the Dysexecutive Questionnaire (DEX; Wilson, Alderman, Burgess, Emslie, \& Evans, 1996). The DEX is a 20- item questionnaire sampling four broad areas of changes commonly associated with dysexecutive syndrome: emotional or personality changes, motivational changes, behavioural changes and cognitive changes. In a pilot studyweused theDEXin a sample of 35 adults with ASD. Large and significant difficulties in areas of daily living associated with executive dysfunction were identified. These difficulties were reminiscent of the executive dysfunction seen in those with acquired dysexecutive syndrome. This was seen in the reports of both the individual themselves, and a close family member. Such widespread difficulties highlighted the impact of a hypothesised executive dysfunction in the day-to-day life of such individuals. In the current study the centrality of deficits in the areas of planning, mental flexibility and generativity was investigated in a high-functioning sample of adults with Asperger syndrome in comparison to wellmatched controls. This approach allows us to assess directly the question of how central deficits in executive functions are in Asperger syndrome. Another prediction of the executive dysfunction theory is that any function that plays a causal role in ASD will be correlated with autistic symptomatology. Thiswas tested explicitly by correlating performance on the measures of executive function with responses to the autism spectrum quotient (Baron- Cohen, Wheelwright, Skinner, Martin, \& Clubley, 2001; completed by the participant) and a communication checklist (Frith, unpublished-see AppendixA; completed by an observer). Both these tests assess day-today behaviour, and can be seen as an index of autistic symptomatology. 
4 Executive processes in Asperger syndrome

Goldsmiths Research Online

Table 1

Group studies that have assessed executive function in adults with autism spectrum disorder (ASD) in comparison to well-matched controls

\begin{tabular}{|c|c|c|c|c|c|c|}
\hline Reference & Diagnosis & $\begin{array}{l}\text { Comparison } \\
\text { groups }\end{array}$ & Age (years) & $\begin{array}{l}\text { Matching criteria } \\
\text { (for all groups) }\end{array}$ & Measures & $\begin{array}{l}\text { Autism } \\
\text { impaired? }\end{array}$ \\
\hline \multirow[t]{11}{*}{ Rumsey (1985) } & Autism & Normal & $18-39$ & Education & WCST & \\
\hline & & & & & No. of categories completed & $\mathrm{Y}$ \\
\hline & & & & & No. of perseverative responses & $\mathrm{Y}^{\mathrm{a}}$ \\
\hline & & & & & No. of perseverative errors & $\mathrm{Y}^{\mathrm{a}}$ \\
\hline & & & & & No. of nonperseverative errors & $\mathrm{Y}^{\mathrm{a}}$ \\
\hline & & & & & Total errors & $\mathrm{Y}$ \\
\hline & & & & & $\begin{array}{l}\text { \% responses accounted for by } \\
\text { perseverative errors }\end{array}$ & $\mathrm{N}$ \\
\hline & & & & & No. of trials to complete first category & $\mathrm{N}$ \\
\hline & & & & & $\begin{array}{l}\% \text { responses accounted for by } \\
\text { conceptual-level responses }\end{array}$ & $\mathrm{N}$ \\
\hline & & & & & Failures to maintain set & $\mathrm{Y}^{\mathrm{a}}$ \\
\hline & & & & & "Learning-to-learn" score & $\mathrm{Y}^{\mathrm{a}}$ \\
\hline \multirow[t]{4}{*}{$\begin{array}{l}\text { Rumsey and } \\
\text { Hamburger (1988) }\end{array}$} & Autism & Normal & $18-39$ & $\begin{array}{l}\text { Age, education, } \\
\text { sex, handedness, } \\
\text { FSIQ }\end{array}$ & WCST & \\
\hline & & & & & No. of categories completed & $\mathrm{Y}$ \\
\hline & & & & & Trail-making (time) & $\mathrm{Y}$ \\
\hline & & & & & Letter fluency & $\mathrm{Y}$ \\
\hline \multirow[t]{2}{*}{$\begin{array}{l}\text { Rumsey and } \\
\text { Hamburger (1990) }\end{array}$} & Autism & $\begin{array}{l}\text { Dyslexic, } \\
\text { normal }\end{array}$ & $18-39$ & $\begin{array}{l}\text { Age, education, } \\
\text { handedness, FSIQ }\end{array}$ & WCST & \\
\hline & & & & & No. of categories completed & $\mathrm{Y}$ \\
\hline \multirow{4}{*}{$\begin{array}{c}\text { Minshew, Muenz, } \\
\text { Goldstein, and } \\
\text { Payton (1992) }\end{array}$} & Autism & Normal & $15-40$ & $\begin{array}{l}\text { Age, sex, race, } \\
\text { FSIQ }\end{array}$ & WCST & \\
\hline & & & & & Perseverative errors & $\mathrm{N}$ \\
\hline & & & & & Nonperseverative errors & $\mathrm{N}$ \\
\hline & & & & & Category fluency & $\mathrm{Y}$ \\
\hline $\begin{array}{l}\text { Minshew, Goldstein, } \\
\text { and Seigel (1995) }\end{array}$ & Autism & Normal & $15-40$ & Age, FSIQ & Letter fluency & $\mathrm{N}$ \\
\hline \multirow[t]{5}{*}{ Turner (1999) } & $\begin{array}{l}\text { High functioning } \\
\text { autism }\end{array}$ & $\begin{array}{l}\text { High } \\
\text { functioning } \\
\text { controls }\end{array}$ & $6-32$ & $\begin{array}{l}\text { Age, NVIQ, } \\
\text { VMA, VIQ }\end{array}$ & Word fluency & $\mathrm{Y}$ \\
\hline & & & & & Ideational fluency & $\mathrm{Y}$ \\
\hline & $\begin{array}{l}\text { Learning disabled } \\
\text { autism }\end{array}$ & $\begin{array}{l}\text { Learning } \\
\text { disabled } \\
\text { controls }\end{array}$ & $6-32$ & $\begin{array}{l}\text { Age, NVIQ, } \\
\text { VMA, VIQ }\end{array}$ & Design fluency & \\
\hline & & & & & Quantity of designs & $\mathrm{N}$ \\
\hline & & & & & Quality of designs & $\mathrm{Y}$ \\
\hline \multirow[t]{10}{*}{ Ozonoff et al. (2004) } & Autism & Normal & $6-47$ & Age, sex, FSIQ & $\begin{array}{l}\text { CANTAB }^{\circledR} \text { (Cambridge Cognition, 1996): } \\
\text { Stockings of Cambridge }\end{array}$ & \\
\hline & & & & & Planning efficiency & $\mathrm{Y}$ \\
\hline & & & & & Initial thinking time & $\mathrm{N}$ \\
\hline & & & & & Subsequent thinking time & $\mathrm{Y}$ \\
\hline & & & & & Simple discrimination & $\mathrm{N}$ \\
\hline & & & & & Simple reversal & $\mathrm{N}$ \\
\hline & & & & & Compound discrimination-separate & $\mathrm{N}$ \\
\hline & & & & & Compound discrimination superimposed & $\mathrm{N}$ \\
\hline & & & & & Compound reversal & $\mathrm{N}$ \\
\hline & & & & & $\begin{array}{l}\text { Intradimensional shift } \\
\text { Extradimensional shift }\end{array}$ & $\begin{array}{l}\mathrm{Y} \\
\mathrm{Y}\end{array}$ \\
\hline \multirow{3}{*}{ Boucher et al. (2005) } & Autism & Normal & Mean: autism, & Age, sex VIO & Brixton test & $\mathbf{N}$ \\
\hline & & & $\begin{array}{l}23 \text { years } 9 \\
\text { months; } \\
\text { control, } 24 \\
\text { years } 2 \text { months }\end{array}$ & & Brixton test & $\mathbf{N}$ \\
\hline & & & & & Hayling test-list two errors & $\mathrm{Y}$ \\
\hline
\end{tabular}


5 Executive processes in Asperger syndrome

Goldsmiths Research Online

\begin{tabular}{|c|c|c|c|c|c|c|}
\hline Reference & Diagnosis & $\begin{array}{l}\text { Comparison } \\
\text { groups }\end{array}$ & Age (years) & $\begin{array}{l}\text { Matching criteria } \\
\text { (for all groups) }\end{array}$ & Measures & $\begin{array}{l}\text { Autism } \\
\text { impaired? }\end{array}$ \\
\hline & & & & & $\begin{array}{l}\text { BADS } \\
\text { Zoo map }\end{array}$ & $\mathrm{N}$ \\
\hline & & & & & Verbal fluency & $\mathrm{N}$ \\
\hline & & & & & Intentional source memory & $\mathrm{N}$ \\
\hline \multirow[t]{16}{*}{ Lopez et al. (2005) } & Autism & Normal & $18-45$ & Age, sex, PIQ & $\begin{array}{l}\text { Delis-Kaplan executive function scales } \\
\text { (Delis, Kaplan and Kramer, 1996): }\end{array}$ & \\
\hline & & & & & California verbal fluency test & $\mathrm{N}$ \\
\hline & & & & & California design fluency test & $\mathrm{N}$ \\
\hline & & & & & No. of perseverative designs & $\mathrm{Y}^{\mathrm{a}}$ \\
\hline & & & & & $\%$ unique designs & $\mathrm{Y}^{\mathrm{a}}$ \\
\hline & & & & & California Stroop test & $\mathrm{N}$ \\
\hline & & & & & Tower of California & $\mathrm{Y}^{\mathrm{a}}$ \\
\hline & & & & & California Trails test & $\mathrm{Y}^{\mathrm{a}}$ \\
\hline & & & & & WAIS & \\
\hline & & & & & $\begin{array}{l}\text { Letter-Number sequencing } \\
\text { WCST }\end{array}$ & $\mathrm{N}$ \\
\hline & & & & & No. of categories & $\mathrm{Y}^{\mathrm{a}}$ \\
\hline & & & & & No. of correct responses & $\mathrm{N}$ \\
\hline & & & & & No. of errors & $\mathrm{Y}^{\mathrm{a}}$ \\
\hline & & & & & No. of perseverative responses & $\mathrm{Y}^{\mathrm{a}}$ \\
\hline & & & & & No. of perseverative errors & $\mathrm{N}$ \\
\hline & & & & & No. of failures to maintain set & $\mathrm{N}$ \\
\hline $\begin{array}{l}\text { Rajendran, Mitchell, } \\
\text { and Rickards } \\
\text { (2005) }\end{array}$ & $\begin{array}{l}\text { High functioning } \\
\text { autism }\end{array}$ & Normal & $11-36$ & $\begin{array}{l}\text { Age, VIQ, PIQ, } \\
\text { FSIQ }\end{array}$ & BADS & $\mathrm{N}^{\mathrm{b}}$ \\
\hline \multirow[t]{3}{*}{ Schmitz et al. (2005) } & $\begin{array}{l}\text { Autism spectrum } \\
\text { disorder }\end{array}$ & Normal & $18-52$ & $\begin{array}{l}\text { Age, handedness, } \\
\text { FSIQ }\end{array}$ & Go/No go task (Rubia et al., 2005) & $\mathrm{N}$ \\
\hline & & & & & Stroop task (Rubia et al., 2005) & $\mathrm{N}$ \\
\hline & & & & & $\begin{array}{l}\text { Modified Meiran Switch task (Meiran, } \\
\text { Hommel, Bibi, \& Lev, 2002; Smith, Taylor, } \\
\text { Brammer, \& Rubia, 2004) }\end{array}$ & $\mathrm{N}$ \\
\hline
\end{tabular}

This list may not be exhaustive. BADS, Behavioural Assessment of Dysexecutive Syndrome; CANTAB, Cambridge Neuropsychological Test Automated Battery; FSIQ, full scale IQ; NVIQ, nonverbal IQ; VIQ, verbal IQ; PIQ, performance IQ; VMA, verbal mental age; WCST, Wisconsin Card Sort Test.

a Indicates non-significant group difference once verbal IQ covaried).

${ }^{\mathrm{b}}$ Reported as approaching significance $(p=0.06)$.

\section{Method}

Atotal of 44 people participated in the study: 22 high-functioning adults with a formal diagnosis of Asperger syndrome (AS; 16 male, 6 female) and 22 normal adult controls (14 male, 8 female). The adults with AS were recruited via various support groups and community centres in the UK. In order to be included in the study, each must have received previously a diagnosis of Asperger syndrome based on APA criteria from a psychiatrist or clinical psychologist who was an expert in this area. The normal adult control groupwas recruited from the subject pool at the Institute of Cognitive Neuroscience, from local community centres and a sixth form college. Each adult with Asperger syndromewas paired individually with a control participant, to match for general ability level (to within four standard score points) and, where possible, age and sex (see Table 2 for further details). General ability was assessed using seven subtests of theWechsler Adult Intelligence Scale (WAIS-III;Wechsler, 1998). Subtests used were picture completion, block 
6 Executive processes in Asperger syndrome

Goldsmiths Research Online

design, picture arrangement, vocabulary, similarities, arithmetic and digit span. These reflect the general pattern of strengths and weaknesses, within the standardWAIS subtests, for those with ASD. Ethics approval for the study was granted by the Joint UCL/UCLH committees on the Ethics of Human Research. Informed consent was obtained from all participants according to the declaration of Helsinki.

Table 2

Mean (S.D.) and range values for age, FSIQ, the Autism Spectrum Quotient (AQ) and Communication Checklist for each participant group

\begin{tabular}{lcc}
\hline & $\begin{array}{l}\text { Asperger } \\
\text { adults }(n=22)\end{array}$ & $\begin{array}{l}\text { Normal adults } \\
(n=22)\end{array}$ \\
\hline Age & $31.09(13.14)$ & $33.45(14.54)$ \\
Range & $16-61$ & $18-64$ \\
FSIQ & $110.5(18.22)$ & $107.91(14.97)$ \\
Range & $80-135$ & $79-135$ \\
AQ (max $=50)^{\mathrm{a}, *}$ & $34.04(6.95)$ & $15.75(8.12)$ \\
Range & $17-46$ & $5-38$ \\
Communication checklist ${ }^{*}$ & $19.41(4.34)$ & $14.09(1.23)$ \\
Range $(13-39)$ & $14-29$ & $13-17$ \\
\hline
\end{tabular}

${ }^{a}$ Data for two normal adults not returned.

${ }^{*} P<0.001$.

\subsection{Experimental investigation}

\subsubsection{Tests of executive function}

1.1.1.1. Behavioural Assessment of the Dysexecutive Syndrome (BADS;Wilson et al., 1996). The full BADS assessment was completed, which includes six subtests. These are:

- Rule Shift Cards test. Mental flexibility is tested by the ability to shift from one rule to another and to keep track of the colour of the previous card and the current rule. The numbers of errors were recorded.

- Action Program test. Novel problem solving is tested by this task which involves physical manipulation of a variety of materials. To solve the task, one has to work backwards, working out what needs to be done, before concentrating on howthat end is to be achieved. The numbers of stages completed successfully were recorded.

- Key Search test. Problem solving is tested by asking the participant to indicate how she/he would search an area to find a lost item. A scoring procedure quantifies how effectively and efficiently the participant covers the search area.

- Temporal Judgement test. Cognitive estimation is tested by asking the participant four questions concerning the length in time of commonplace events (e.g. how long would it take to clean the windows of an average sized house). The number of correct responses was recorded.

- Zoo Map test. Planning is tested by asking participants to show how they would visit a series of designated locations on a map of a zoo. Whilst doing so, certain rules must be obeyed. There is a high demand and a low demand trail. In the high demand trail, participants must plan in advance the order in which to visit the places. In the low demand trial, participants must simply follow the instructions to produce an error free score. Accuracy on the two trials and the time taken to complete them were recorded. 
- Six Elements test. Planning, organisation and monitoring of behaviour are tested using this multi-component task. Participants must carry out six separate tasks (two dictation, two arithmetic and two picture-naming tasks), within $10 \mathrm{~min}$, whilst obeying a simple rule (do not carry out two of the same tasks consecutively). Whilst participants are not expected to complete each task, they must carry out at least part of all six. It is not important how well the participant performs the individual component tasks. Performance is measured as the number of tasks attempted, the number of rule breaks, and the maximum time spent on any individual subtask.

1.1.1.2. Hayling test (Burgess \& Shallice, 1997). Response initiation and suppression are measured by this test which comprises two parts. In the first part, 15 incomplete sentences are read aloud and must be completed by aword that makes the sentence meaningful (e.g. 'he posted the letter without a ... stamp'). In the second part, 15 further sentences are presented which have to be completed by a word that does not fit into the context of the sentence (e.g. 'the captain wanted to stay with the sinking ... toaster'). Four scores were of interest-time taken part one (response initiation), time taken part two, errors part two (response suppression, strategy formation) and overall efficiency score.

1.1.1.3. Modi.ed Card Sorting test (MCST; Nelson, 1976). On this measure of mental flexibility, the participant must sort cards on one of three possible dimensions (colour, number, shape) according to an unspoken rule. After correctly sorting six cards, the participant must shift to sort the cards along a different dimension. The experimenter tells the participant whether she/he has placed each card correctly, but does not give the participant the rule explicitly. Total number of errors, number of perseverative errors and number of categories obtained were recorded.

1.1.1.4. Stroop test (Trenerry, Crosson, DeBoe, \& Leber, 1989). Inhibition of a dominant verbal response is tested using the Stroop test. In part 1 (low demand condition), participants are required to read aloud colour words as quickly as possible. The colour word is written in an ink which is of an incongruent colour. In part 2 (high demand condition), participants are required to name the colour of the ink, rather than read aloud the word. The number of words read in 120 $\mathrm{s}$ was recorded (if all items were read within the time limit, a score of 112 - the total number of items - was recorded).

1.1.1.5. Trail-making test (Army Individual Test Battery, 1944). This task assesses psychomotor speed, visual scanning and, in the second part, cognitive flexibility. In part A, the participant must draw a line linking the numbers $1-25$ in consecutive order. In part $B$, the participant must draw a line linking alternating numbers and letters in ascending order (A-L; 1-13) as quickly but as accurately as possible. In both cases, time taken (including time to correct any errors) was recorded.

1.1.1.6. Verbal .uency. Generativity is tested by asking the participant to list as many different words as possible beginning with the same letter in $60 \mathrm{~s}$. The letters F, Aand S were used in three separate trials. The test was administered using instructions as described in (Lezak, 1995). Total number of words generated was recorded.

\subsubsection{Measures of autistic symptomatology}

1.1.2.1. Autism Spectrum Quotient (AQ; Baron-Cohen et al., 2001). This selfadministered 50-item questionnaire was developed to measure the extent to which an adult with normal intelligence has the traits associated with the autism spectrum. Participants rate their own behaviour in the areas of social skill, attention switching, attention to detail, communication and imagination on a fourpoint scale (definitely agree, slightly agree, slightly disagree, definitely disagree). Although we should note that the AQ is not specifically a diagnostic tool, a score of $32 / 50$ is given as a useful cut-off for distinguishing those who have clinically significant levels of autistic traits when conducting a general population study. For a clinic referred sample, a cut-off score of 26 has recently been proposed (Woodbury-Smith, Robinson, Wheelwright, \& Baron-Cohen, 2005). Testretest and inter-rater reliability of the AQ is reported to be good (Baron- Cohen et al., 2001), and discriminant power as moderate (Woodbury-Smith et al., 2005). Furthermore, individuals on the 
broader autism phenotype (in this case parents of children with autism) have been found to score significantly higher than controls on the social skills and communication subscales of the AQ (Bishop et al., 2004).

1.1.2.2. Communication Checklist (Frith, unpublished; see Abell et al., 1999). This 13-item checklist (see Appendix A) was used to assess verbal and nonverbal communication in each individual. It is based on observation and was completed by two raters by discussion. The checklist is divided into three sections - speech, language and body language - and each of the 13 items are rated on a three-point scale.

\section{Results}

Data were analysed first in the traditional manner, looking for group differences. The results of this analysis were used to focus the direction of the subsequent analyses, that of the multiple case series. ${ }^{1}$

\subsection{Group difference analysis}

Performance on all test measures was subjected to group analysis using independent $t$-tests or Mann-Whitney tests as appropriate, according to the nature of the distribution of scores in each group on each test. Overall 11 of 22 comparisons showed a significant group difference in performance, and it is these measures that formed the focus of the remaining investigation. As can be seen in Table 3, these findings show mixed performance on tests of executive functions in a group of able adults with Asperger syndrome. For the most part, the performance of the adults with Asperger syndrome was similar to, or significantly worse than that of their well-matched peers. However, on the temporal judgement subtest of the BADS, the group of adults with Asperger syndrome was significantly better able to estimate the time required for four commonplace activities than the control group. Thus as a group, and in relation to a well-matched control group, evidence for intact and impaired ability is identified, with impaired ability being identified predominantly in the newer tests of executive function (the Action Program, Zoo Map and Six Elements subtests of the BADS as well as the Hayling test). In terms of the classic tests of executive function adopted in the study, only performance on the Trailmaking test distinguished between the two participant groups. The AS participants were significantly slower than their peers on both parts of this test, although performance on the test of psychomotor speed (part A) showed a greater difference than performance on the test thought to tap cognitive flexibility (part B). Correlations between performance on the two parts of the test were found in both the AS group $[r=0.59$ (20) $p<0.01]$, and the control group $[r=0.422$ (20) $p=0.051]$, although the latter just failed to reach significance. As a result of this, the group comparison of Trailmaking part B was rerun, with performance on part A being entered as a covariate in the analysis. Once slower psychomotor skill had been accounted for in this way, no group differences remained in the speed of performance on part $\mathrm{B}[F(1,41)=0.01, p=0.92]$. Thus, while this was the only one of the traditional tests of executive function to show a group difference, this difference reflects difficulties in psychomotor processing and visual search rather than in executive dysfunction.

A similar concern arose with respect to performance on the Hayling test. While there was no difference in the errors produced by the two participant groups, the AS group was signifi- cantly slower than their peer group on both parts of this test (part 1, initiation; part 2, inhibition and strategy formation). Correlations between latencies on the two parts of the test were found in the AS group [ $r(19)=0.85, p<0.001]$, and in the control group $[r(20)=0.45, p<0.05]$. As a result of this, the group comparison of latencies on part 2 of the Hayling test was rerun,

\footnotetext{
${ }^{1}$ A small number of missing data points exist which arose: one AS participant was experiencing a stutter at the time of testing and therefore provided no data on tasks requiring a speeded linguistic response; one control was colour-blind and did not undertake the Stroop test.
} 
with performance at time 1 being entered as a covariate in the analysis. Once slower initiation had been accounted for in this way, no group differences remained in the latency to respond in the second part of the test $[F(1,40)=0.07, p=0.79]$. Thus, this difference appears to reflect difficulties in initiation per se, rather than in inhibition or strategy formation. However, there was a clear group difference in overall score on the Hayling test, as well as a significant correlation between this measure and performance on the Stroop test (another test of inhibition) in the AS group only [AS, $r(19)=0.45, p<0.05$; controls, $r(19)=0.19, p=0.42$ ]. This suggests that performance on the Hayling test is a useful test of inhibition in an AS sample.We will return to performance on this test when describing the multiple case series analysis below.

\begin{tabular}{|c|c|c|c|}
\hline & Asperger adults & Normal adults & \\
\hline \multicolumn{4}{|l|}{ BADS } \\
\hline Rule Shift errors & $1.32(2.23)[0-8]$ & $0.27(0.63)[0-2]$ & n.s. \\
\hline Action Program score & $3.55(0.80)[1-4]$ & $3.91(0.43)[2-4]$ & $\cdot$ \\
\hline Key Search total & $12.41(3.40)[6-16]$ & $12.82(3.53)[6-16]$ & n.s. \\
\hline Temporal Judgement score & $1.96(0.90)[0-3]$ & $1.32(0.78)[0-3]$ & $* *$ \\
\hline Zoo Map 1 score & $4.31(4.26)[-4$ to 8$]$ & $6.68(2.66)[0-8]$ & * \\
\hline Zoo Map 2 score & $7.86(0.64)[5-8]$ & $7.96(0.21)[7-8]$ & n.s. \\
\hline Zoo Map total score & $12.18(4.18)[4-16]$ & $14.64(2.65)[8-16]$ & $\cdot$ \\
\hline Six Elements: no tasks completed & $4.91(1.48)[1-6]$ & $5.91(0.29)[5-6]$ & $*$ \\
\hline Six Elements: rule breaks & $2.38(0.63)[0-2]$ & $0.0(0.0)$ & n.s. \\
\hline Six Elements: longest time & $234.24(115.53)[116-596]$ & $169.18(32.60)[114-256]$ & $\cdot$ \\
\hline BADS total & $17.43(3.16)[12-22]$ & $19.09(2.22)[12-22]$ & n.s. \\
\hline \multicolumn{4}{|l|}{ Hayling test } \\
\hline Hayling time 1 & $22.86(30.32)[0-133]$ & $6.91(4.20)[0-15]$ & * \\
\hline Hayling time 2 & $60.57(72.86)[0-325]$ & $25.23(20.31)[2-93]$ & $\cdot$ \\
\hline Hayling 2 total errors & $5.29(8.46)[0-29]$ & $2.46(4.13)[0-19]$ & n.s. \\
\hline Hayling overall total & $16.29(3.62)[10-22]$ & $18.59(1.65)[14-21]$ & $*$ \\
\hline \multicolumn{4}{|l|}{ MCST } \\
\hline No. of categories & $5.55(1.10)[2-6]$ & $5.91(0.29)[5-6]$ & n.s. \\
\hline Total errors & $5.0(5.00)[0-17]$ & $4.77(2.91)[0-11]$ & n.s. \\
\hline Perseverative errors & $0.82(1.47)[0-6]$ & $0.73(0.83)[0-3]$ & n.s. \\
\hline Stroop & $98.48(16.20)[59-112]$ & $104.10(15.18)[54-112]$ & n.s. \\
\hline Trails A & $40.86(17.85)[18-78]$ & $23.66(7.34)[12.31-43]$ & $\cdots *$ \\
\hline Trails B & $85.14(50.16)[29-245]$ & $58.80(23.08)[32.15-127]$ & $\cdot$ \\
\hline Verbal fluency & $45.86(11.45)[28-63]$ & $47.96(10.51)[31-74]$ & n.s. \\
\hline
\end{tabular}

2.1.1. Relationship between tests of executive function, the AQ and the Communication Checklist Correlations were conducted to examine the association between the measures of executive function, the AQ and the communication checklist in the Asperger group (This analysis was conducted only on those measures showing data that were normally distributed). There was a relationship between performance measures on certain executive tests and both the AQ and the communication checklist, although these were seen predominantly for the latter comparison (four versus two; see Table 4). The significant correlations were seen only between the measures of autistic symptomatology and parts of the newer tests of executive function, specifically the action program and six elements subtasks of the BADS and the Hayling test. The relationship between these variables is shown in Fig. 1.

In summary, the findings of the group and correlational analyses in two groups well matched for sex, age and intellectual ability, provides some evidence for a deficit in executive functions in Asperger syndrome. However, many of the tests showed no impairment in the performance of the AS group. This leads to the question of the causal nature of an executive deficit in Asperger syndrome. Is a deficit seen in all participants, or is a deficit seen in a subgroup of those with AS? In order to evaluate this, we conducted a detailed individual case analysis of performance using a multiple case series approach. 
10 Executive processes in Asperger syndrome

Goldsmiths Research Online
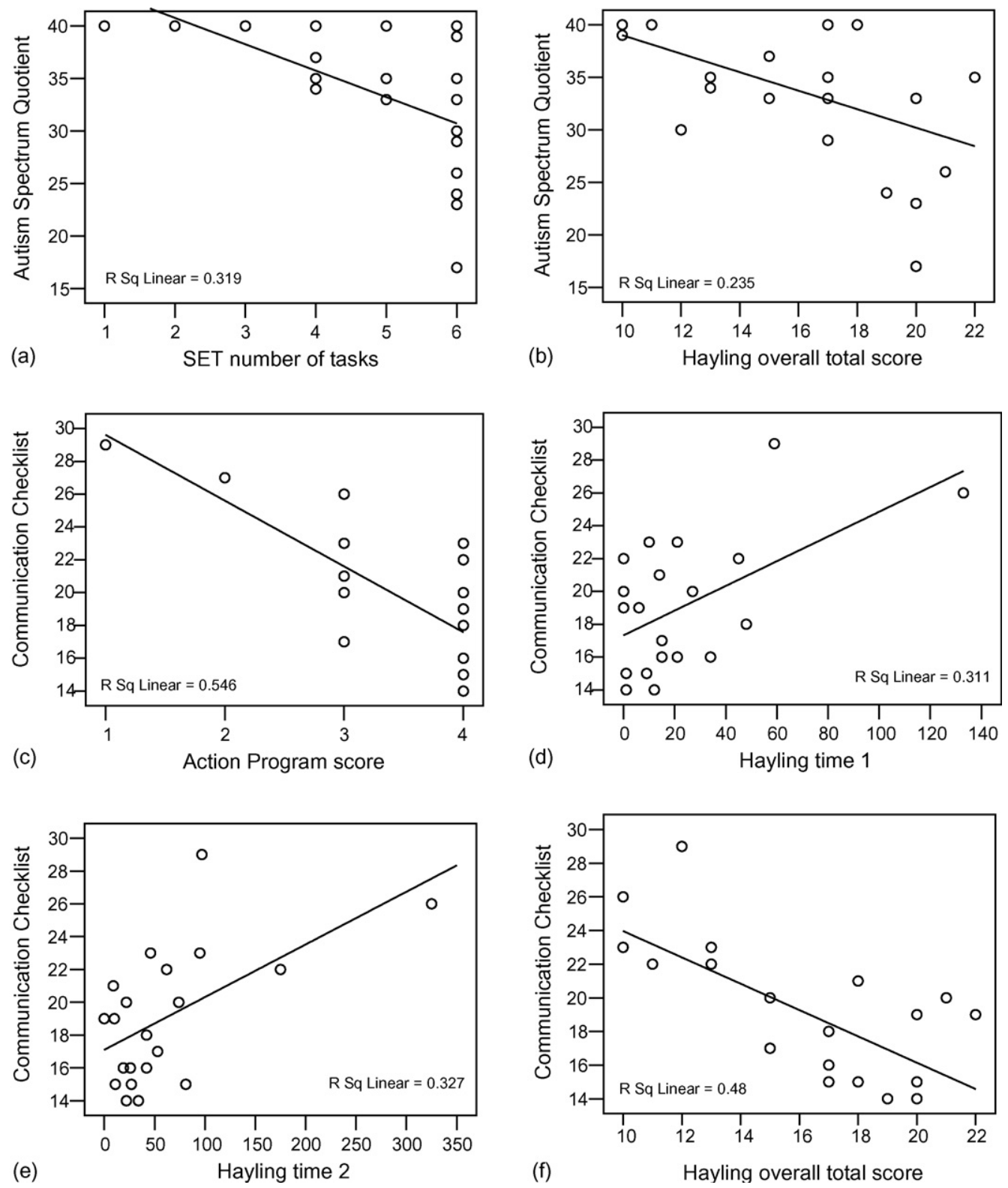

Fig. 1. Scatterplots showing relationship in adults with Asperger syndrome between: (a) AQ and SET number of tasks completed; (b) AQ and Hayling overall total; (c) CC and action program score; (d) CC and Hayling time 1; (e) CC and Hayling time 2. 
11 Executive processes in Asperger syndrome

Goldsmiths Research Online

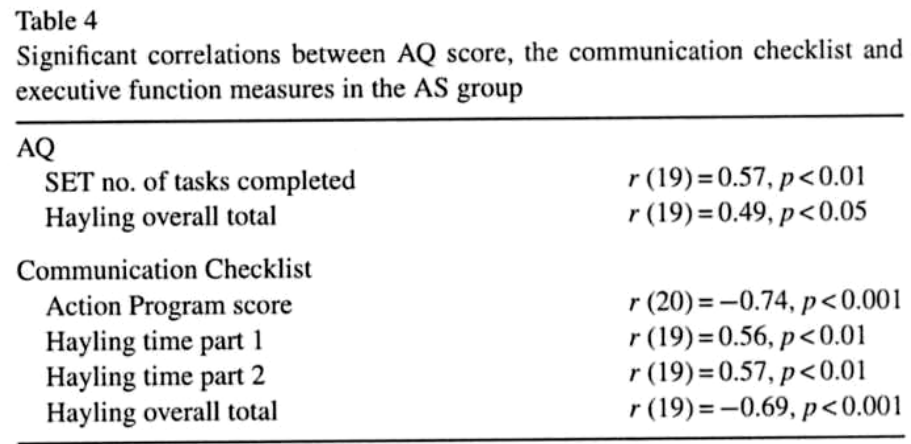

SET: Six Elements test.

\subsection{Multiple case series analysis}

Only those measures in which the performance of the control group was normally distributed were included in the case series analysis (see Table 5). In order to identify those participants with Asperger syndrome who fell outside of the normal distribution we compared each individual with the whole control group on every performance measure. We adopted the procedure of Crawford and Garthwaite (2002) for comparing a single case with a modestly sized control group. This procedure uses the $t$-distribution, which is more resistant to departures from normality in the control group than the standard methodology of using $z$-scores. It provides a conservative method for identifying individuals that fall below the 5 th percentile of normal performance. We followed the method of Ramus et al. (2003) for defining the normal range. First, the control mean and standard deviation was calculated and control participants who qualified for atypical performance - falling belowthe 5 th percentile of the $t$-distribution - were removed (usually none and never more than two control adults). Second, the control mean, S.D. and number of cases were recalculated and the AS participants falling below the $5 \%$ cut-off were identified and considered as outliers. Once outliers had been identified, comparison across tasks and domains was made. The number of outliers identified for each task is shown in Table 5. Here, outliers are seen in some of the classic tests of executive function, as well as in the newer tests. 
12 Executive processes in Asperger syndrome

Goldsmiths Research Online

Table 5

Measures subjected to multiple case series analysis (tasks on which performance of the control group was normally distributed), and number of AS outliers (\% AS group) on each test measure

\begin{tabular}{lll}
\hline & $\begin{array}{l}\text { No. of AS } \\
\text { participants }\end{array}$ & $\begin{array}{l}\text { No. of outliers } \\
(\%)\end{array}$ \\
\hline $\begin{array}{l}\text { Executive function tests } \\
\text { BADS total }\end{array}$ & 21 & $0(0)$ \\
Temporal Judgement score & 22 & $0(0)$ \\
Key Search total & 22 & $0(0)$ \\
Six Elements test: longest time & 21 & $13(61.90)$ \\
Hayling time part 1 & 21 & $8(38.09)$ \\
Hayling time part 2 & 21 & $8(38.09)$ \\
Hayling errors part 2 & 21 & $0(0)$ \\
Hayling overall total & 21 & $8(38.09)$ \\
MCST total & 22 & $4(18.18)$ \\
MCST perseveration & 22 & $3(13.64)$ \\
Trail-making part A & 22 & $13(59.09)$ \\
Trail-making part B & 22 & $7(31.82)$ \\
Verbal fluency & 21 & $0(0)$ \\
Other tests & & \\
AQ & 22 & $18(81.82)$ \\
Communication Checklist & 22 & $14(63.64)$ \\
\hline
\end{tabular}

\subsubsection{Relationship between tests of executive function, the AQ and the Communication Checklist}

With reference to the multiple case series analysis, we now consider the relationship between performance on the six elements and Hayling tests - both tests which are apparently highly sensitive to AS - and two measures of autistic symptomatology: the AQ and the Communication Checklist. First, comparison was made of the outliers identified on the SET longest time, the AQ and the Communication Checklist (see Fig. 2). It is clear that combinations of these three measures account well for the AS outliers. Only one individual with AS was an outlier on each measure alone and only one was unimpaired on all three measures. Table 6 shows those individuals considered as outliers on each test measure included in the study.

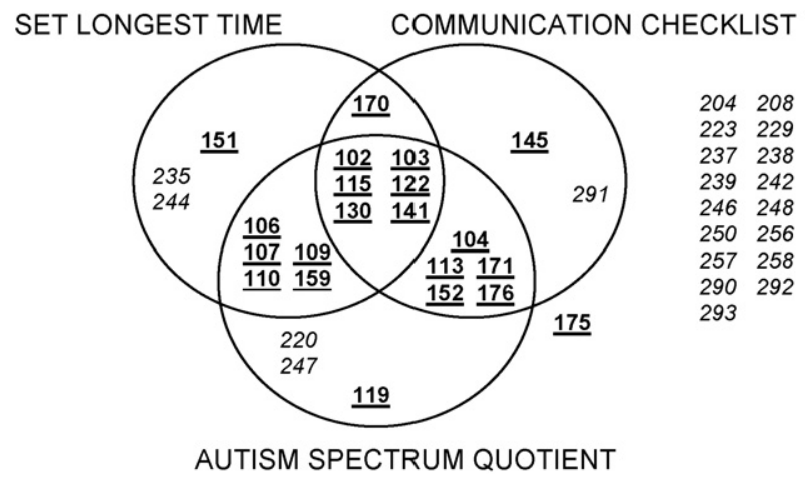

Fig. 2. Outliers identified on the SET longest time, the AQ and the Communication Checklist (adults with Asperger syndrome; controls).

The qualitative performance of the AS group was also distinguished from that of their peers in some cases: as the SET longest time difference shows, those with AS were more likely to get engrossed in one particular subtask at the expense of the other five subtests. This was particularly clear in the case of one 44-year-old male (id122) who first attempted a dictation task and ended 
13 Executive processes in Asperger syndrome

Goldsmiths Research Online

up talking for the full $10 \mathrm{~min}$, thereby failing to complete any of the other SET subtests. Other examples are the case of a 22-year-old female who stopped for long periods of time (id103) or that of a 16-year-old male who spent a very short period of time on each of the six SET subtests and then settled now to complete one subtest in detail, knowing that he had ful- filled the rule 'complete something from all tests' (id170). These behaviours were not seen in any of the control participants.

When comparing performance on the Hayling overall total score to the AQ and the Communication Checklist, it is clear that the total score on the Hayling test alone does not account for any of the AS outliers (see Fig. 3). As shown in Table 4 (see also Fig. 1), there was a strong correlation between Hayling overall total score and score on the Communication Checklist in those with AS (r (19) =-0.69, p < 0.001) such that those making more errors on the Hayling test were rated as more 'odd' on the communication checklist. Furthermore, as shown in Fig. 3, all those with AS who were identified as outliers on the Hayling overall total measure were also identified as outliers on the Communication Checklist. This suggests that there is some process involved in the Hayling test that is linked to verbal and non-verbal communication and that when impaired creates a perception of oddness in another person. 
Originally published: Neuropsychologia 44 (2006) 2822-2835

\begin{tabular}{|c|c|c|c|c|c|c|c|c|c|c|c|c|c|c|c|c|c|}
\hline & $\mathrm{CC}^{*}$ & $\mathrm{AQ}^{*}$ & $\begin{array}{c}\text { BADS } \\
\text { total }\end{array}$ & $\begin{array}{c}\text { Key } \\
\text { search } \\
\text { total }\end{array}$ & $\begin{array}{c}\text { Key } \\
\text { search } \\
\text { profile }\end{array}$ & $\begin{array}{l}\text { Temp. } \\
\text { judge. } \\
\text { profile* }\end{array}$ & $\begin{array}{c}\text { Zoo } \\
\text { map } \\
\text { profile }\end{array}$ & $\begin{array}{c}\text { SET } \\
\text { time* }\end{array}$ & $\begin{array}{l}\text { Hayling } \\
\text { Time } 1^{\star}\end{array}$ & \begin{tabular}{|l|} 
Hayling \\
Time $2^{\star}$
\end{tabular} & \begin{tabular}{|c|} 
Hayling \\
overall \\
total $^{*}$
\end{tabular} & $\begin{array}{l}\text { MCST } \\
\text { total } \\
\text { errors }\end{array}$ & $\begin{array}{l}\text { MCST } \\
\text { persev- } \\
\text { erations }\end{array}$ & $\begin{array}{c}\text { Trails } \\
A^{*}\end{array}$ & $\begin{array}{c}\text { Trails } \\
\mathrm{B}^{\star}\end{array}$ & $\begin{array}{c}\text { Fluency } \\
*\end{array}$ & $\begin{array}{c}\% \\
\text { outliers }\end{array}$ \\
\hline 102 & & & & & & & & & & & & & & & & & 29 \\
\hline 103 & & & & & & & & & & & & & & & & & 53 \\
\hline 104 & & & & & & & & & & & & & & & & & 47 \\
\hline 106 & & & & & & & & & & & & & & & & & 18 \\
\hline 107 & & & & & & & & & & & & & & & & & 12 \\
\hline 109 & & & & & & & & & & & & & & & & & 47 \\
\hline 110 & & & & & & & & & & & & & & & & & 29 \\
\hline 113 & & & & & & & & & & & & & & & & & 41 \\
\hline 115 & & & & & & & & & & & & & & & & & 53 \\
\hline 116 & & & & & & & & n.a. & n.a. & n.a. & n.a. & & & & & n.a. & 33 \\
\hline 119 & & & & & & & & & & & & & & & & & 18 \\
\hline 122 & & & & & & & & & & & & & & & & & 18 \\
\hline 130 & & & & & & & & & & & & & & & & & 29 \\
\hline 141 & & & & & & & & & & & & & & & & & 35 \\
\hline 145 & & & & & & & & & & & & & & & & & 6 \\
\hline 151 & & & & & & & & & & & & & & & & & 18 \\
\hline 152 & & & & & & & & & & & & & & & & & 27 \\
\hline 159 & & & & & & & & & & & & & & & & & 24 \\
\hline 170 & & & & & & & & & & & & & & & & & 13 \\
\hline 171 & & & & & & & & & & & & & & & & & 44 \\
\hline 175 & & & & & & & & & & & & & & & & & 6 \\
\hline 176 & & & & & & & & & & & & & & & & & 18 \\
\hline$\%$ outliers & $\overline{64}$ & 82 & 0 & 0 & 0 & 0 & 5 & 62 & 38 & 38 & 38 & 18 & 14 & 59 & 32 & 0 & \\
\hline
\end{tabular}

Table 6a Individual profiles of performance for each adult (adults with Asperger syndrome)

Shaded cells show participants whose performance fell outside of the normal distribution (outliers, see Table 5 for description of process to establish outliers). *Significant group difference (see Table 3). AQ: Autism Spectrum Quotient (Baron-Cohen et al., 2001); CC: Communication Checklist (Frith, unpublished; see Appendix A); BADS: Behavioural Assessment of the Dysexecutive Syndrome (Wilson et al., 1996); Hayling: Hayling test (Burgess \& Shallice, 1997); MCST: Modified Card Sorting Test (Nelson, 1976); Trails: Trailmaking test (Army Individual Test Battery, 1944); Fluency: test of verbal fluency (for administration, see Lezak, 1995). 
Goldsmiths Research Online. (C) The Authors (2006)

Originally published: Neuropsychologia 44 (2006) 2822-2835

\begin{tabular}{|c|c|c|c|c|c|c|c|c|c|c|c|c|c|c|c|c|c|}
\hline & $\mathrm{CC}^{*}$ & $\mathrm{AQ}^{*}$ & $\begin{array}{c}\text { BADS } \\
\text { total }\end{array}$ & $\begin{array}{c}\text { Key } \\
\text { search } \\
\text { total }\end{array}$ & $\begin{array}{c}\text { Key } \\
\text { search } \\
\text { profile }\end{array}$ & $\begin{array}{l}\text { Temp. } \\
\text { judge. } \\
\text { profile* }\end{array}$ & $\begin{array}{c}\text { Zoo } \\
\text { map } \\
\text { profile }\end{array}$ & $\begin{array}{c}\text { SET } \\
\text { time* }\end{array}$ & $\begin{array}{l}\text { Hayling } \\
\text { Time 1* }\end{array}$ & \begin{tabular}{|l|} 
Hayling \\
Time 2*
\end{tabular} & $\begin{array}{c}\text { Hayling } \\
\text { overall } \\
\text { total }\end{array}$ & $\begin{array}{l}\text { MCST } \\
\text { total } \\
\text { errors }\end{array}$ & $\begin{array}{l}\text { MCST } \\
\text { persev- } \\
\text { erations }\end{array}$ & Trails $A^{*}$ & $\begin{array}{c}\text { Trails } \\
\mathrm{B}^{*}\end{array}$ & $\begin{array}{c}\text { Fluency } \\
*\end{array}$ & $\begin{array}{c}\% \\
\text { outliers }\end{array}$ \\
\hline 204 & & & & & & & & & & & & & & & & & 0 \\
\hline 208 & & & & & & & & & & & & & & & & & 0 \\
\hline 220 & & & & & & & & & & & & & & & & & 12 \\
\hline 223 & & & & & & & & & & & & & & & & & 0 \\
\hline 229 & & & & & & & & & & & & & & & & & 0 \\
\hline 235 & & & & & & & & & & & & & & & & & 6 \\
\hline 237 & & & & & & & & & & & & & & & & & 18 \\
\hline 238 & & & & & & & & & & & & & & & & & 6 \\
\hline 239 & & & & & & & & & & & & & & & & & 0 \\
\hline 242 & & & & & & & & & & & & & & & & & 6 \\
\hline 244 & & & & & & & & & & & & & & & & & 6 \\
\hline 246 & & & & & & & & & & & & & & & & & 0 \\
\hline 247 & & & & & & & & & & & & & & & & & 6 \\
\hline 248 & & & & & & & & & & & & & & & & & 0 \\
\hline 250 & & & & & & & & & & & & & & & & & 12 \\
\hline 256 & & & & & & & & & & & & & & & & & 0 \\
\hline 257 & & & & & & & & & & & & & & & & & 0 \\
\hline 258 & & & & & & & & & & & & & & & & & 6 \\
\hline 290 & & & & & & & & & & & & & & & & & 0 \\
\hline 291 & & & & & & & & & & & & & & & & & 6 \\
\hline 292 & & & & & & & & & & & & & & & & & 0 \\
\hline 293 & & & & & & & & & & & & & & & & & 0 \\
\hline$\%$ outliers & 5 & 9 & 0 & 0 & 0 & 0 & 0 & 9 & 0 & 5 & 9 & 5 & 5 & 5 & 9 & 0 & \\
\hline
\end{tabular}

Table $6 \mathrm{~b}$ Individual profiles of performance for each adult (control participants [all outliers were excluded in the first stage of the outlier analysis, except for participant 220 on ASQ and participant 237 on trails B])

Shaded cells show participants whose performance fell outside of the normal distribution (outliers, see Table 5 for description of process to establish outliers). *Significant group difference (see Table 3). AQ: Autism Spectrum Quotient (Baron-Cohen et al., 2001); CC: Communication Checklist (Frith, unpublished; see Appendix A); BADS: Behavioural Assessment of the Dysexecutive Syndrome (Wilson et al., 1996); Hayling: Hayling test (Burgess \& Shallice, 1997); MCST: Modified Card Sorting Test (Nelson, 1976); Trails: Trailmaking test (Army Individual Test Battery, 1944); Fluency: test of verbal fluency (for administration, see Lezak, 1995). 


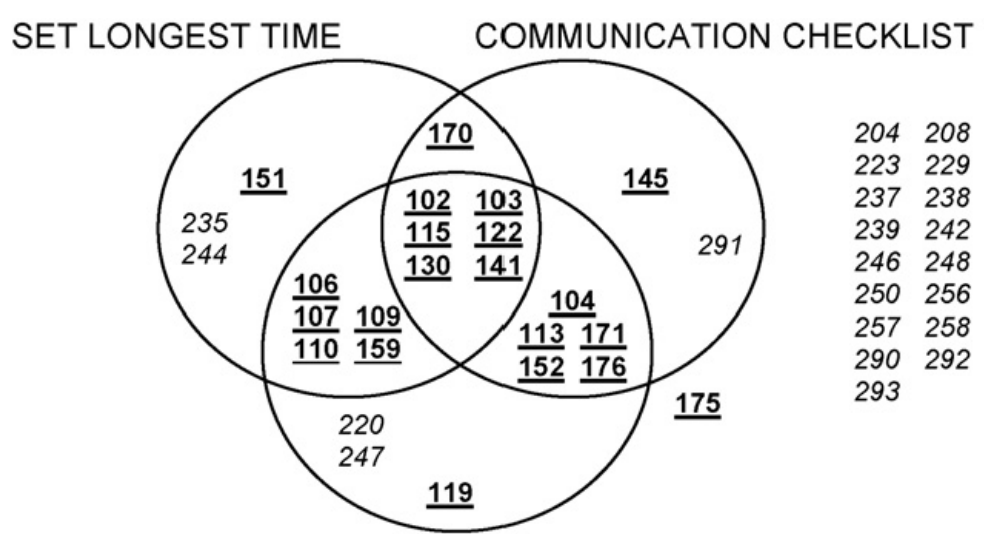

AUTISM SPECTRUM QUOTIENT

Fig. 3. Outliers identified on the Hayling overall total, the $A Q$ and the Communication Checklist (adults with Asperger syndrome; controls).

\section{Discussion}

In the present investigation we assessed a relatively large group of adults with Asperger syndrome on a comprehensive battery of tests of executive functions. Their performance was compared with that of a very well-matched group of normally developing adults. Overall, there were no differences between those with and without AS on all 'classical' tests of executive function, once difficulties in psychomotor processing and visual search had been accounted for (cf. group difference on trails A and B). However, surprisingly large differences were found on other, newer tests of executive function, in particular on the Six Elements task of the BADS and on the Hayling test. These tests were sensitive not only at a group level but also on a case-by-case basis and they correlated with measures of autistic behaviours. Existing data from the Six Elements task, in particular, points to an interpretation of these findings. For example, Burgess (1997) confirmed that this task is crucially related to planning, organisation and action monitoring. Furthermore, Burgess, Alderman, Evans, Emslie, and Wilson's (1998) factor analysis of the DEX questionnaire (see below) and performance on a range of behavioural tests of executive function suggested that dysexecutive syndrome might fractionate at the behavioural level. Specifically, those individuals who performed particularly poorly on the Six Elements test, but within the range of a control group (matched to the patient group for meanNARTreading IQ), on a range of other executive tests - including the MCST, Trailmaking and verbal fluency tasks completed in the current study - were seen as having a particular difficulty in response initiation and intentionality. An alternative, but perhaps overlapping, explanation would be as a difficulty in goal/sub-goal coordination. According to Ward and Allport (1997), a sub-goal is an essential, but indirect, part of the solution of a task. Goal/subgoal coordination is a critical component of the Six Elements test. Further support for this view in relation to autism comes from a set of unpublished studies of children with autism. Sykes (2001) adapted a paradigm developed out of the work of Ward (1993) using the Tower of London. One of the over-riding conclusions of these studies was that children with autism begin to have difficulty on tower-type puzzles only when sub-goal moves are introduced into the puzzles. Overall, then, the findings of the current study suggest that greatest dysfunction appeared in response initiation and intentionality-the ability to engage and disengage actions in the service of overarching goals. By showing this, our study has provided support for the existence of deficits in specific aspects of executive function in Asperger syndrome. At this point it is unclear whether these deficits are causal to autistic disorder. However, by combining evidence from a group analysis, multiple case series (outlier) analysis, 
17 Executive processes in Asperger syndrome

Goldsmiths Research Online

and from the correlations between executive measures and the two relatively new measures of autistic symptomatology included in the study we have been able to provide preliminary evidence for a link between a certain pattern of executive dysfunction and the aspects of autistic symptomatology that were assessed in our study. This provides stronger evidence than is obtained purely from the executive function data, or from the use of any one of the three analyses alone. To further strengthen our findings, it will be important to validate the Communication Checklist, and to have more detailed evaluation of the Autism Spectrum Quotient, in order to compare behavioural performance on test measures with subsections of these tests.

There are three main reasons why the population assessed in the present study provides a particularly good test of the theory that executive function is central to ASD. First, Asperger syndrome might be considered to be the purest form of autism in the sense that it is unimpeded by the effects of learning dif- ficulty, for example (Frith, 2004). Therefore, any deficits that are related causally to autistic symptomatology should be most clearly observable in highfunctioning individuals with ASD, i.e. those with Asperger syndrome. Second, by assessing adults we avoid issues concerning the late maturation of the frontal lobes that may cloud the picture in studies of children and adolescents (especially when these groups are compared with their typically developing peers). It should be noted, however, that this study did not address any potential compensatory strategies that may have effected the performance of our adult group. Third, by carefully selecting an IQ-matched control group we again move away from complications in interpreting results in the light of ability level.

We administered a large range of tests of executive functions. Interestingly, no significant group differences were found on any of the tests that are considered to be 'classical' executive tests, after controlling for psychomotor speed (the MCST, Stroop test, Trail-making test and verbal fluency). The multiple case analyses did reveal executive dysfunction on some performance measures of these tests in a minority of AS individuals. Nevertheless, significant group differences were found on certain newer tests, particularly the Six Elements and Hayling tests. These tests also correlated with autistic symptomatology and a high proportion of the AS group performed below the $5^{\text {th }}$ percentile with reference to the controls. Both of these tests have been shown to have reasonable ecological validity (Odhuba, Broek, \& Johns, 2005, respectively). Thus, we can expect that the AS participants in our study will experience a degree of executive dysfunction in their everyday living. This position is supported by the data from AS individuals who have been administered theDEXquestionnaire (Channon et al., 2001, Hill \& Bird, unpublished data). In the future, it will be necessary to identify which dysexecutive behaviours seen in day-to-day life are related directly to specific executive deficits in adults with Asperger syndrome. A recent study has made some progress in this respect, investigating the relationship between executive functions (using the recently published Delis-Kaplin executive function scale; Delis, Kaplan, \& Kramer, 2001; see Table 1), and restricted, repetitive behaviours, which are a diagnostic feature of the autism spectrum. In this study, a model of executive strengths (working memory and response inhibition) and weaknesses (planning and cognitive flexibility) best predicted the severity of restricted, repetitive behaviours reported in a group of adults with ASD (Lopez et al., 2005).

While the data that we have presented are indicative of specific difficulty in at least two aspects of executive function - what has been termed response initiation and intentionality by Burgess et al. (1998) - the possibility remains that we have identified a general dysexecutive syndrome rather than specific deficits. This might be the case if the Six Elements and Hayling tests were simply more sensitive to generalised executive dysfunction than other executive tests, rather than to specific difficulties. More research needs to be conducted to address this question. By further assessing a wide range of executive functions in the same sample, we can continue to address the question of whether we can identify a specific profile of strengths and weaknesses in Asperger syndrome, or whether the disorder represents general executive dysfunction. Furthermore, careful neuroimaging studies will help to identify whether normal brain activations are seen in those with Asperger syndrome when completing tasks on which their behavioural performance falls in the normal range. To date, it seems that this is not the case (e.g. Boucher et al., 2005; Schmitz et al., 2005). 
18 Executive processes in Asperger syndrome

Goldsmiths Research Online

Our data support those reported by a number of other researchers who have shown deficits in executive function in the autism spectrum (see Table 1 and Hill, 2004a,b). Turner (1999) reported a correlational link in autistic individuals between poor performance on ideational and design fluency tasks and high levels of repetitive behaviour in daily life. More recently Ozonoff et al. (2004) reported a correlation between impairment on the Stockings of Cambridge and ID/ED shift subtests of the Cambridge Neuropsychological Test Automated Battery (CANTAB $®$, Cambridge Cognition, 1996) and adaptive behaviour (as measured by the Vineland Adaptive Behaviour Scales, Sparrow, Balla, \& Cicchetti, 1984). However, CANTAB performance did not predict autism severity or specific autism symptoms (measured by the ADI-R and ADOS; Lord, Rutter, \& Le Couteur, 1994, respectively).We might expect, that children and adults with a lower general ability level and/or more severe autistic features would show the executive deficits identified here in addition to other deficits in the executive domain. This could reflect either more general executive dysfunction in the lower ability ranges or impoverished cognitive skills in nonexecutive domains.

If executive dysfunction is central to the autism spectrum then the profile of performance of those with ASD on executive tests should differ from those with other developmental disorders that have also been associated with executive dysfunction. While the performance of children with attention deficit hyperactivity disorder (ADHD) has been reported to be poor in relation to matched controls on both the Six Elements and Hayling tests (Siklos \& Kerns, 2004; Shallice et al., 2002, respectively), overall the evidence suggests that children with ADHD and ASD show differing profiles on tests of executive function (see Sergeant, Geurts, \& Oosterlaan, 2002 for a review; but see also Goldberg et al., 2005). Specifically, in a comparison of children with ASD, ADHD and Tourette syndrome, Ozonoff and Jensen (1999) reported differential performance between the groups on a test of planning, cognitive flexibility and inhibition. Those with ASD were shown to have difficulties only on the tests of planning and cognitive flexibility, while the children withADHDhad difficulties only on the test of inhibition. The performance of the current adult sample on the Stroop task, conceived as a test of inhibition, supports this view. It remains a possibility that tasks requiring other attentive processes than inhibition (for example, sustained attention) may be impaired in ASD. Tasks such as the Test of Everyday Attention (Robertson,Ward, Ridgeway, \& Nimmo-Smith, 1994) and the Sustained Attention to Response Test (SART; Robertson, Manly, Andrade, Baddeley, \& Yiend, 1997) might be useful in testing this. It seems likely, however, that differing profiles of executive dysfunction can be identified in those with different developmental disorders. With time, patterns of executive dysfunction might act as behavioural markers of different disorders.

Given that we have identified a very specific neuropsychological performance profile in our sample of adults with Asperger syndrome, is it possible to speculate about its neuroanatomical cause? While we must be wary of drawing parallels between acquired and developmental disorders, the performance of our AS sample appears to mirror a number of findings reported in the literature. For example, multitasking (which requires considerable numbers of executive functions) has been shown to be impaired in patients who have acquired frontal lobe damage (particularly to rostral prefrontal cortex), even when an executive function deficit is small or indeed undetectable using traditional neuropsychological tests such as theWisconsin Card Sorting test and verbal fluency (e.g. Burgess, 2000). There is now increasing evidence of frontal lobe abnormalities in individuals with ASD (see Cody, Pelphrey, \& Piven, 2002 for a review), including evidence of a significantly slower rate of increase in frontal lobe white matter across the 2-11-year age range (Carper, Moses, Tigue,\&Courchesne, 2002). In typical development, the frontal lobes are those that take the longest to mature postnatally and the rostral prefrontal cortex is one of the last areas to achieve myelination (e.g. Huttenlocher, 1979; Fuster, 1997). These regions may therefore be particularly susceptible to the influence of atypical development in other brain areas, even though the consequences of this may appear subtle in some situations, and this might explain the profile that we have observed. Certainly, the frontal lobes must remain vulnerable long after other brain areas are fully matured and this could lead these areas to be particularly susceptible to slow increases in the frontal lobe 
19 Executive processes in Asperger syndrome

Goldsmiths Research Online

white matter described by Carper and Courchesne (2000), or to poor neural pruning (as speculated to occur in ASD; Frith, 2003).

In summary,we have provided support for executive dysfunction in a group of adults with Asperger syndrome, suggesting that executive dysfunction is central to the disorder. Specifically, response initiation and intentionality, in particular the ability to engage and disengage actions in the service of overarching goals, are impaired. This might also be seen as a difficulty in goal/sub-goal coordination such as that described by Ward and Allport (1997). These deficits are best observed by using a range of tests of executive function, and particularly those that have some degree of ecological validity (see studies by Klin for similar arguments in the social domain, e.g. Klin, Jones, Schultz, \& Volkmar, 2003). Furthermore, we have highlighted the importance of both between- and within-group analysis methods to identify the extent of executive dysfunction across participants, as well as the need to link these to autistic symptomatology.

\section{Acknowledgements}

This research was facilitated by the MRC Co-operative in 'Analysis of cognitive impairment and imaging of cognition' at UCLand supported by funding from the UK's Medical Research Council (grant no. G9716841 to Uta Frith). The data were collected while the first author worked at the Institute of Cognitive Neuroscience.We gratefully acknowledge the willing participation of all individuals in this study. We are indebted to Philip Angell and Sarah White for help with data collection, as well as to Uta Frith and Paul Burgess for discussions regarding the study.

\section{Appendix A}

Communication Checklist (developed by Uta Frith, unpublished). One or more raters complete the Communication Checklist after spending some time with the individual concerned. Each item is scored on a three-point scale - normal (1), slightly odd (2), very odd (3) - resulting in a score between 13 and 39 . 


\begin{tabular}{llll}
\hline Speech & & & \\
Intonation & Normal & Slightly odd & Very odd \\
Stress & Normal & Slightly odd & Very odd \\
Speed & Normal & Slightly odd & Very odd \\
Volume & Normal & Slightly odd & Very odd \\
Language & & & \\
Content & Normal & Slightly odd & Very odd \\
Grammar & Normal & Slightly odd & Very odd \\
Socially adapted & Normal & Slightly odd & Very odd \\
Topic maintenance & Normal & Slightly odd & Very odd \\
Body language & & & \\
Eye contact & & Slightly odd & Very odd \\
Gestures & Normal & Slightly odd & Very odd \\
Posture/gait & Normal & Slightly odd & Very odd \\
Facial expression & Normal & Slightly odd & Very odd \\
Proximity to others & Normal & Slightly odd & Very odd \\
\hline
\end{tabular}

\section{References}

Abell, F., Krams, M., Ashburner, J., Passingham, R., Friston, K., Frackowiak, R., et al. (1999). The neuroanatomy of autism: a voxel-based whole brain analysis of structural scans. Neuroreport, 10(8), 16471651.

American Psychiatric Association (1994). Diagnostic and statistical manual of mental disorders. Washington DC: American Psychiatric Association.

Baron-Cohen, S., Wheelwright, S., Skinner, R., Martin, J.,\&Clubley, E. (2001). The autism spectrum quotient (AQ): evidence from Asperger syndrome, high-functioning autism, males and females, scientists and mathematicians. Journal of Autism and Developmental Disorders, 31(1), 5-17.

Adjutant General'sOffice (1944). Army individual test battery.War Department, Adjutant General's Office.

Bishop, D. V. M., Maybery, M., Maley, A.,Wong, D., Hill,W., \& Hallmayer, J. (2004). Using self-report to identify the broad phenotype in parents of children with autistic spectrum disorders: a study using the Autism-spectrum quotient. Journal of Child Psychology and Psychiatry, 45(8), 1431- 1436.

Boucher, J., Cowell, P., Howard, M., Broks, P., Farrant, A., Roberts, N., et al. (2005). A combined clinical, neuropsychological, and neuroanatomical study of adults with high functioning autism. Cognitive Neuropsychiatry, 10(3), 165-213.

Burgess, P.W. (1997). Theory and methodology in executive function research. In P. Rabbitt (Ed.), Methodology of frontal and executive functions. Hove: LEA.

Burgess, P.W. (2000). Strategy application disorder: the role of the frontal lobes in human multitasking. Psychological Research, 63, 279-288. 
21 Executive processes in Asperger syndrome

Goldsmiths Research Online

Burgess, P. W., Alderman, N., Evans, J. J., Emslie, H., \& Wilson, B. A. (1998). The ecological validity of tests of executive function. Journal of the International Neuropsychological Society, 4, 547-558.

Burgess, P. W., Alderman, N., Forbes, C., Costello, A., Coates, L., Dawson, D. R., et al. (2006). The case for the development and use of "ecologically valid" measures of executive function in experimental and clinical neuropsychology. Journal of the International Neuropsychological Society, 12, 194-209.

Burgess, P. W., \& Shallice, T. (1997). The Hayling and Brixton tests. Bury, St. Edmonds: Thames Valley Test Company.

Cambridge Cognition. (1996). CANTAB. Cambridge: Cambridge Cognition Ltd.

Caramazza, A., \& McCloskey, M. (1988). The case for single-patient studies. Cognitive Neuropsychology, 5(5), $517-528$.

Carper, R. A.,\&Courchesne, E. (2000). Inverse correlation between frontal lobe and cerebellum sizes in children with autism. Brain, 123, 836-844.

Carper, R. A., Moses, P., Tigue, Z. D., \& Courchesne, E. (2002). Cerebral lobes in autism: early hyperplasia and abnormal age effects. Neuroimage, 16, 1038-1051.

Channon, S., Charman, T., Heap, J., Crawford, S., \& Rios, P. (2001). Reallife- type problem-solving in Asperger's syndrome. Journal of Autism and Developmental Disorders, 31(5), 461-469.

Cody, H., Pelphrey, K., \& Piven, J. (2002). Structural and functional magnetic resonance imaging of autism. International Journal of Developmental Neuroscience, 766, 1-18.

Crawford, J. R., \& Garthwaite, P. H. (2002). Investigation of the single case in neuropsychology: confidence limits on the abnormality of test scores and test score differences. Neuropsychologia, 40, 1196-1208.

Delis, D., Kaplan, E., \& Kramer, J. (1996). The California executive function tests. San Antonio, Texas: The Psychological Corporation.

Delis, D., Kaplan, E., \& Kramer, J. (2001). The California executive function tests. San Antonio, Texas: The Psychological Corporation.

Frith, C. (2003). What do imaging studies tell us about the neural basis of autism? In M. Rutter (Ed.), Autism: neural basis and treatment possibilities. Chichester, Wiley: Novartis Foundation.

Frith, U. (2004). Emmanuel Miller lecture: confusions and controversies about Asperger syndrome. Journal of Child Psychology and Psychiatry, 45, 659-686.

Fuster, J. M. (1997). The prefrontal cortex: anatomy physiology and neuropsychology of the frontal lobe. Lippincott-Raven.

Goldberg, M. C., Mosotofsky, S. H., Cutting, L. E., Mahone, E. M., Astor, B. C., Denckla, M. B., et al. (2005). Subtle executive impairment in children with autism and children with ADHD. Journal of Autism and Developmental Disorders, 35(3), 279-293.

Hill, E. L. (2004a). Evaluating the theory of executive dysfunction in autism. Developmental Review, 24, 189233 .

Hill, E. L. (2004b). Executive dysfunction in autism. Trends in Cognitive Sciences, 8, 26-32.

Huttenlocher, P. R. (1979). Synapticdensity in human frontal cortex-developmental changes and effects of aging. Brain Research, 163, 195-205.

Klin, A., Jones, W., Schultz, R., \& Volkmar, F. (2003). The enactive mind, or from actions to cognition: lessons from autism. Philosophical Transactions of the Royal Society, Series B, 358(1430), 345-360.

Lezak, M. (1995). Neuropsychological assessment. Oxford: Oxford University Press. 
22 Executive processes in Asperger syndrome

Goldsmiths Research Online

Lopez, B. R., Lincoln, A. J., Ozonoff, S., \& Lai, Z. (2005). Examining the relationship between executive functions and restricted, repetitive symptoms of autistic disorder. Journal of Autism and Developmental Disorders, 35(4), 445-460.

Lord, C., Risi, S., Lambrecht, L., Cook, E. H., Leventhal, B. L., DiLavore, P. C., et al. (200o). The autism diagnostic observation schedule-generic: a standard measure of social and communication deficits associated with the spectrum of autism. Journal of Autism and Developmental Disorders, 30, 205-223.

Lord, C., Rutter, M., \& Le Couteur, A. (1994). Autism diagnostic interviewrevised: a revised version of a diagnostic interview for caregivers of individuals with possible pervasive developmental disorders. Journal of Autism and Developmental Disorders, 24, 659-685.

Marshall, J. C., \& Newcombe, F. (1984). Putative problems and pure progress in neuropsychological singlecase studies. Journal of Clinical Neuropsychology, 6, 65-70.

McCloskey, M. (2001). The future of cognitive neuropsychology. In B. Rapp (Ed.), The handbook of cognitive neuropsychology: what de.cits reveal about the human mind (pp. 593-610). Hove, UK: Psychology Press.

Meiran, N., Hommel, B., Bibi, U., \& Lev, I. (2002). Consciousness and control in task switching. Conscious Cognition, 11, 10-33.

Mesulam, M.-M. (2002). The human frontal lobes: transcending the default mode through contingent encoding. In D. T. Stuss, \& R. T. Knight (Eds.), Principles of frontal lobe function. Oxford: Oxford University Press.

Minshew, N. J., Goldstein, G., \& Seigel, D. J. (1995). Speech and language in high-functioning autistic individuals. Neuropsychology, 9, 255-261.

Minshew, N. J., Muenz, L. R., Goldstein, G., \& Payton, J. B. (1992). Neuropsychological functioning in nonmentally retarded autistic individuals. Journal of Clinical and Experimental Neuropsychology, 14(5), 749761.

Nelson, H. E. (1976). A modified card sorting test sensitive to frontal lobe defects. Cortex, 12, 313-324.

Odhuba, R. A., Broek, M. D. v. d., \& Johns, L. C. (2005). Ecological validity of measures of executive functioning. British Journal of Clinical Psychology, 44, 269-278.

Ozonoff, S., Cook, I., Coon, H., Dawson, G., Joseph, R. M., Klin, A., et al. (2004). Performance on Cambridge neuropsychological test automated battery subtests sensitive to frontal lobe function in people with autistic disorder: evidence from the collaborative programs of excellence in autism network. Journal of Autism and Developmental Disorders, 34(2), 139-150.

Ozonoff, S., \& Jensen, J. (1999). Specific executive function profiles in three neurodevelopmental disorders. Journal of Autism and Developmental Disorders, 29(2), 171-177.

Pennington, B. F.,\&Ozonoff, S. (1996). Executive functions and developmental psychopathology. Journal of Child Psychology and Psychiatry, 37(1), 51-87.

Rabbitt, P. (1997). Methodology of frontal and executive function. Psychology Press.

Rajendran, G., Mitchell, P., \& Rickards, H. (2005). How do individuals with Asperger syndrome respond to nonliteral language and inappropriate requests in computer-mediated communication. Journal of Autism and Developmental Disorders, 35(4), 429-443.

Ramus, F., Rosen, S., Dakin, S., Day, B. L., Castellote, J. M., White, S., et al. (2003). Theories of developmental dyslexia: insights from a multiple case study of dyslexic adults. Brain, 126, 841-865.

Roberts, A. C., Robbins, T.W., \&Weiskrantz, L. (1998). The prefrontal cortex. Executive and cognitive functions. Oxford: Oxford University Press. 
23 Executive processes in Asperger syndrome

Goldsmiths Research Online

Robertson, I. H., Manly, T., Andrade, J., Baddeley, B. T., \& Yiend, J. (1997). 'Oops!': performance correlates of everyday attentional failures in traumatic brain injured and normal subjects. Neuropsychologia, 35(6), 747758.

Robertson, I. H., Ward, V., Ridgeway, V., \& Nimmo-Smith, I. (1994). The test of everyday attention. Bury, St. Edmunds, UK: Thames Valley Test Company.

Rubia, K., Lee, F., Cleare, A., Tunstall, N., Fu, C., \& McGuire, P. (2005). Acute tryptophan depletion reduces right inferior prefrontal activation during response inhibition in fast, event related fMRI.

Psychopharmacology (Berl), 1432-2072.

Rumsey, J. M. (1985). Conceptual problem-solving in highly verbal nonretarded autistic men. Journal of Autism and Developmental Disorders, 15(1), 23-36.

Rumsey, J. M.,\&Hamburger, S.D. (1988). Neuropsychological findings in highfunctioning men with infantile autism, residual state. Journal of Clinical and Experimental Neuropsychology, 10(2), 201-221.

Rumsey, J. M., \& Hamburger, S. D. (1990). Neuropsychological divergence of high-level autism and severe dyslexia. Journal of Autism and Developmental Disorders, 20(2), 155-168.

Russell, J. (Ed.). (1997). Autism as an executive disorder. Oxford: Oxford University Press.

Schmitz, N., Rubia, K., Daly, E., Smith, A., Williams, S., \& Murphy, D. G. M. (2005). Neural correlates of executive function in autistic spectrum disorders. Biological Psychiatry.

Sergeant, J. A., Geurts, H., \& Oosterlaan, J. (2002). How specific is a deficit of executive functioning for attention-deficit/hyperactivity disorder? Behavioural Brain Research, 130, 3-28.

Shallice, T., Marzocchi, G. M., Coser, S., Del Savio, M., Meuter, R. F., \& Rumiati, R. I. (2002). Executive function profile of children with attention deficit hyperactivity disorder. Developmental Neuropsychology, 21(1), 43-71.

Siklos, S.,\&Kerns, K. A. (2004). Assessing multitasking in children with ADHD using a modified six elements test. Archives of Clinical Neuropsychology, 19, 347-361.

Smith, A., Taylor, E., Brammer, M. J., \& Rubia, K. (2004). Neural correlates of switching set as measured in fast, event-related functional magnetic resonance imaging. Human Brain Mapping, 21, 247-256.

Sparrow, S. S., Balla, D. A.,\&Cicchetti, D. V. (1984). Vineland adaptive behavior scales. American Guidance Service.

Stuss, D. T., \& Knight, R. T. (2002). Principles of frontal lobe function. Oxford: Oxford University Press.

Sykes, E. D. A. (2001). Planning in autism: the role of working memory. Unpublished PhD Thesis. University of Cambridge, Cambridge.

Trenerry, M. R., Crosson, B., DeBoe, J., \& Leber, W. R. (1989). Stroop neuropsychological screening test. Psychological Assessment Resources.

Turner, M. A. (1999). Generating novel ideas: fluency performance in highfunctioning and learning disabled individuals with autism. Journal of Child Psychology and Psychiatry, 40(2), 189-201.

Ward, G. (1993). An experimental investigation of executive processes. Unpublished D.Phil. Thesis. University of Oxford.

Ward, G., \& Allport, A. (1997). Planning and problem-solving using the fivedisc Tower of London task. Quarterly Journal of Experimental Psychology, 50A(1), 49-78.

Wechsler, D. (1998). Wechsler adult intelligence scale revised. The Psychological Corporation.

Wilson, B. A., Alderman, N., Burgess, P. W., Emslie, H., \& Evans, J. J. (1996). Behavioural assessment of the dysexecutive syndrome. Thames Valley Test Company. 
24 Executive processes in Asperger syndrome

Goldsmiths Research Online

Woodbury-Smith, M. R., Robinson, J., Wheelwright, S., \& Baron-Cohen, S. (2005). Screening adults for Asperger syndrome using theAQ: a preliminary study of its diagnostic validity in clinical practice. Journal of Autism and Developmental Disorders, 35(3), 331-335. 